\title{
SCREENING FOR OPHTHALMIC MANIFESTATIONS OF SICKLE CELL DISEASE IN THE UNITED KINGDOM
}

\author{
D. $\mathrm{KENT}^{1}$, R. ARYA ${ }^{2}$, W. A. ACLIMANDOS ${ }^{1}$, A. J. BELLINGHAM ${ }^{2}$ \\ and A. C. BIRD ${ }^{3}$ \\ London
}

\begin{abstract}
SUMMARY
There are marked variations in the manifestations of sickle disease in different populations. The ocular complications of this condition amongst the Afro-Caribbeans living in the United Kingdom have not previously been reported. We present the preliminary results of an ophthalmic screening programme at King's College Hospital, London. One hundred eyes of 50 patients with sickle cell disease were assessed. Full ocular examination was performed including fundus fluorescein angiography. We have looked at the haematological and clinical profile of the patients involved as well as the number of days spent in hospital during the year preceding the eye examination. The incidence of grade II retinopathy was found to be significantly higher than grade $\mathrm{I}$ in SC disease. This concurs with the results of the Jamaican screening and confirms that these patients are at higher risk of visual impairment than those with SS disease. Our results also agree with the Jamaican experience which suggest that visual morbidity is mostly due to complications of proliferative sickle retinopathy (PSR). However, the findings in patients without proliferative changes are different; in particular, angioid streaks leading to disciforms are an important cause of visual loss in Jamaica, but were not seen in any of the 98 eyes examined in this study. No correlation was found between the grade of retinopathy and age, sex, systemic complications and various haematological parameters except for the percentage of haemoglobin $F$, which was significantly higher in patients with grade I (7.6) compared with grade II (4.2) retinopathy $(p=0.0127)$.
\end{abstract}

The complications of sickle cell disease vary significantly in different populations. ${ }^{1,2}$ The retinopathy associated with the different types of sickle disease has been well documented in various parts of the world. ${ }^{3-5}$ Sickle cell retinopathy can cause significant alteration to the retinal

From: 'Ophthalmic Department, King's College Hospital, London, UK; ${ }^{2}$ Haematology Department, King's College Hospital, London, UK; ${ }^{3}$ Institute of Ophthalmology and Moorfields Eye Hospital, London, UK.

Correspondence to: Mr W. A. Aclimandos, Ophthalmic Department, King's College Hospital, Denmark Hill, London SE5 9RS, UK. circulation. It is one of the commonest causes of peripheral proliferative retinopathy. In one study $49 \%$ of proliferative retinopathy was due to sickle cell disease. ${ }^{6} \mathrm{~A}$ cohort study performed on Jamaican children found peripheral retinal vessel closure in approximately $50 \%$ of SS and SC genotypes at the age of 6 years and this increased to affect $90 \%$ of children by the age of 12 years. ${ }^{4}$ As the size of the Afro-Caribbean population living in the United Kingdom is increasing an estimate of the potential morbidity resulting from sickle cell retinopathy is important. In Camberwell, South London, $21.4 \%$ of the local population are of African or Caribbean origin, and over 600 are known to be affected by sickle cell diseases and attend the Haematology Department at King's College Hospital. No information is available in the literature concerning sickle cell retinopathy in Britain while the prevalence of some other complications of sickle cell disease have been shown to be different from those seen in other communities. ${ }^{7.8} \mathrm{We}$ established an ophthalmic screening programme aiming to examine the prevalence of significant ophthalmic manifestations and to optimise delivery of ophthalmology services to this at-risk group.

\section{PATIENTS AND METHODS}

This programme was approved by the local ethics committee. Non-consenting patients were reassured that their non-participation would not affect their overall management. A database records all known cases of sickle cell disease in the Camberwell Health Authority and the relevant details applicable to a patient such as first presentation at the Haematology Department, sickle-related history, genotype, all relevant laboratory data including present haematological status and past blood transfusions, as well as past and present management objectives.

All patients on this database were invited to participate in the study. Ocular assessment included details of family and past ocular history, visual acuity, fundus examination with mydriatrics, as well as fundus fluorescein angiography unless specifically contraindicated. Funduscopic findings such as the presence and position of retinal vas*

Eye (1994) 8, 618-622 C 1994 Royal College of Ophthalmologists 


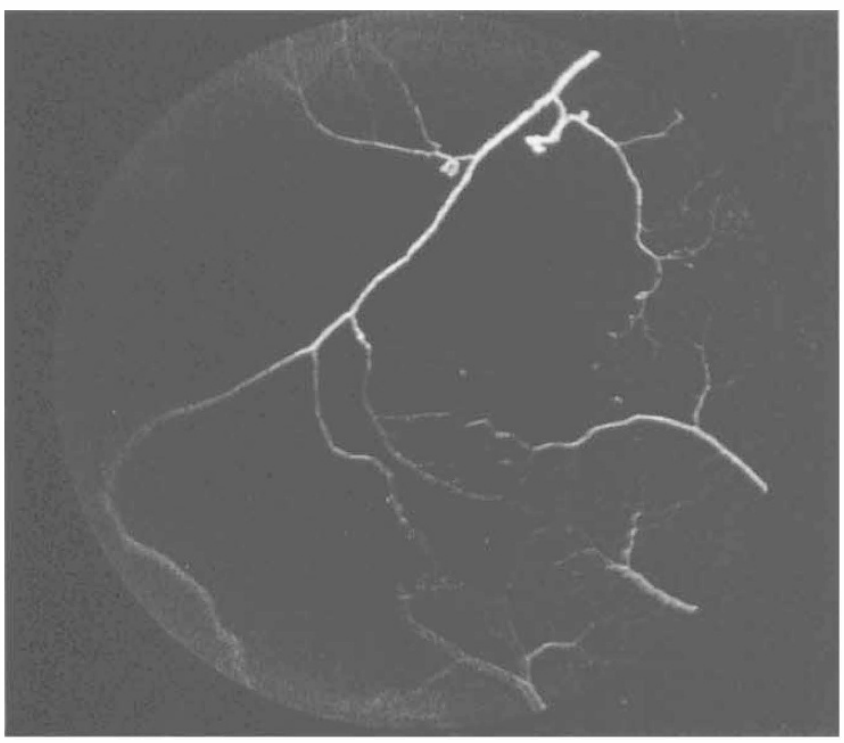

Fig. 1. Grade I retinopathy.

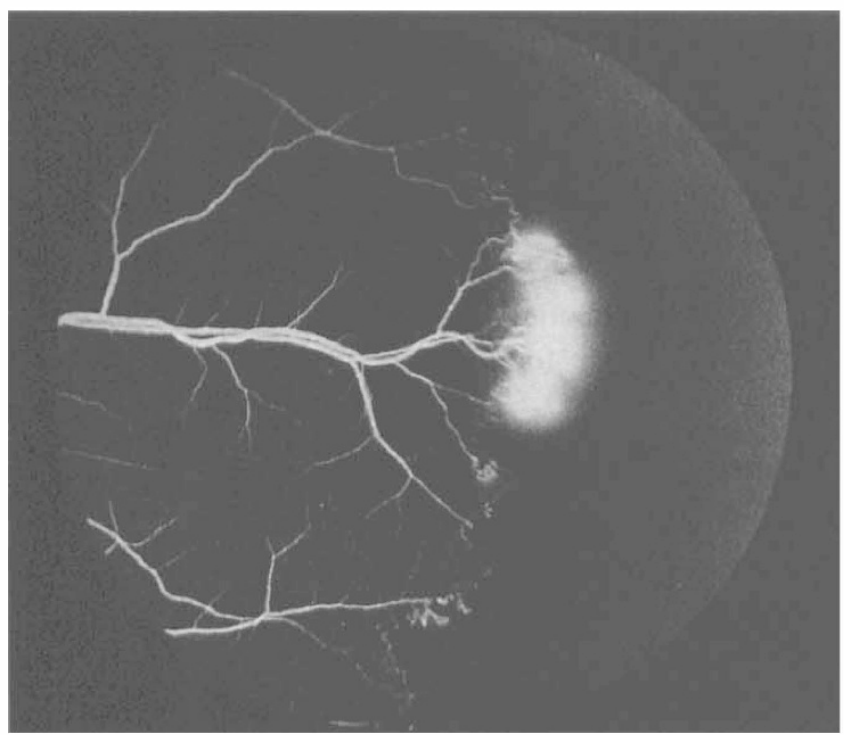

Fig. 3. Grade II retinopathy + proliferative sickle retinopathy (PSR).

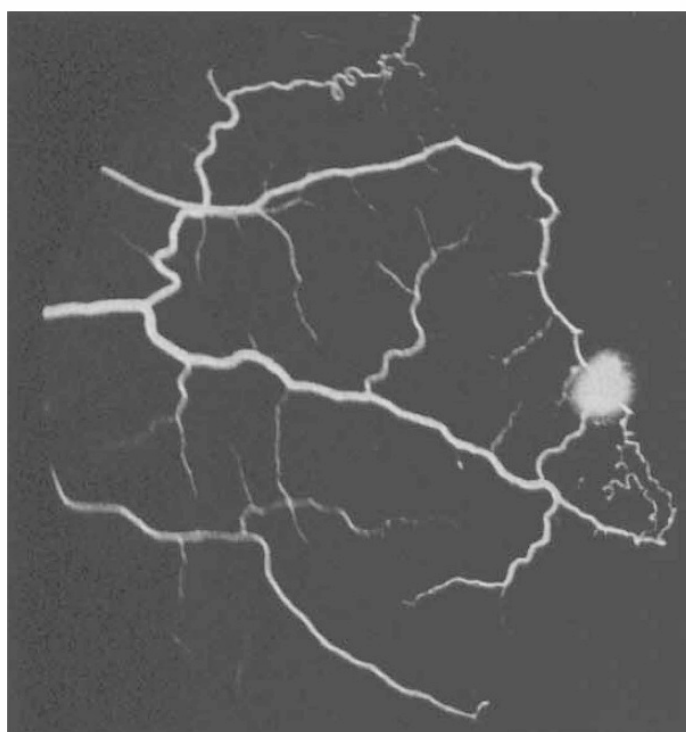

Fig. 5. Grade IIb retinopathy $+P S R$.

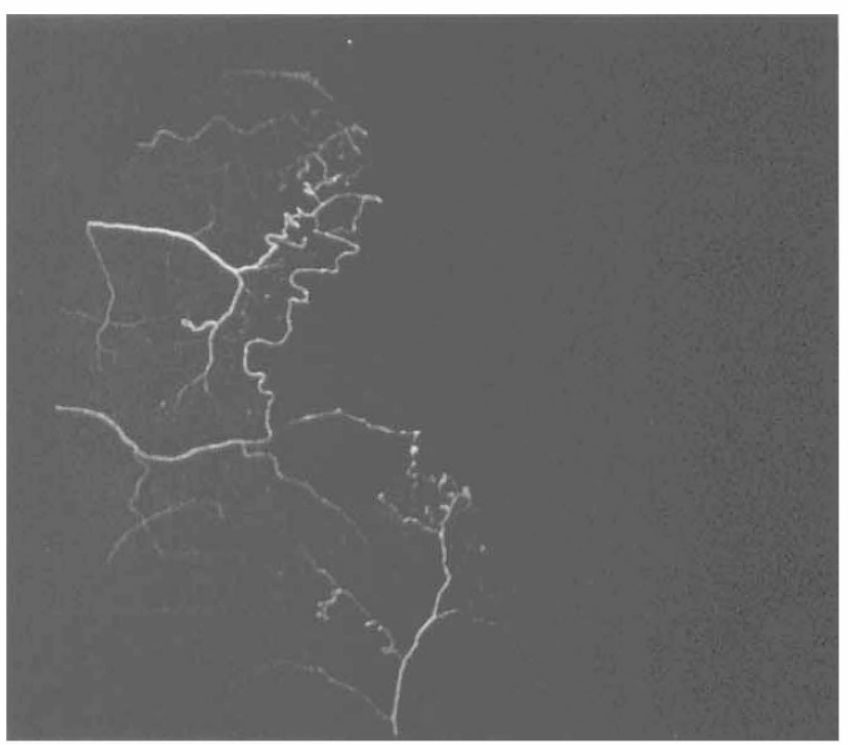

Fig. 2. Grade IIa retinopathy.

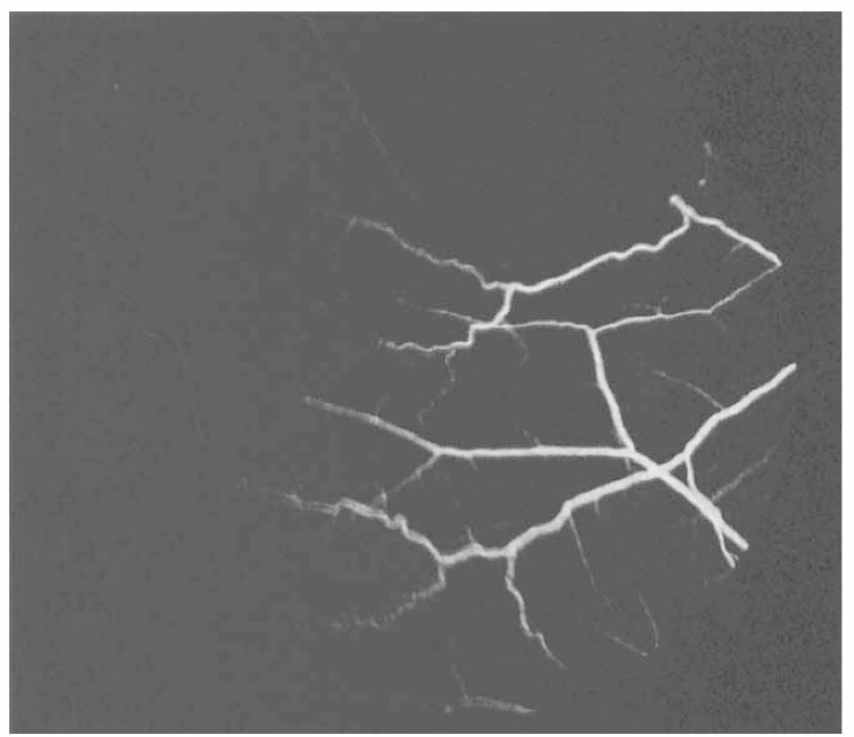

Fig. 4. Grade IIb retinopathy.

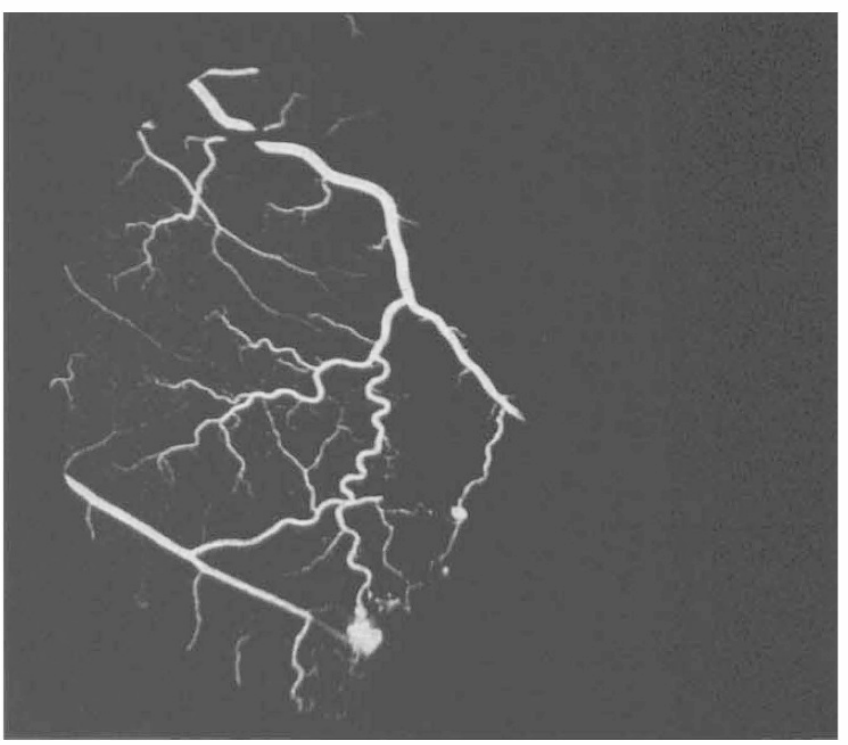

Fig. 6. Grade III retinopathy. 
Table I. Patients with visual acuity $<6 / 18$

\begin{tabular}{|c|c|c|c|c|c|c|c|c|}
\hline Sex & $\begin{array}{l}\text { Age } \\
(\mathrm{yr})\end{array}$ & $\begin{array}{c}\text { Geno- } \\
\text { type }\end{array}$ & $\begin{array}{l}\text { Visual } \\
\text { acuity }\end{array}$ & $\begin{array}{l}\text { Patho- } \\
\text { logy }\end{array}$ & $\begin{array}{c}\mathrm{Hb} \\
(\mathrm{g} / \mathrm{dl})\end{array}$ & $\begin{array}{l}\mathrm{HbF} \\
(\%)\end{array}$ & $\begin{array}{r}\text { PCV } \\
(\%)\end{array}$ & $\begin{array}{c}\text { RDW } \\
(\%)\end{array}$ \\
\hline M & 30 & SC & NPL & Cat.RD & 12.4 & 0.8 & 34 & 17 \\
\hline M & 26 & SC & PL & RD & - & - & - & $-^{a}$ \\
\hline $\mathrm{F}$ & 23 & SS & $6 / 18$ & Toxo. & 12.1 & 2.1 & 22 & 24 \\
\hline $\mathrm{F}$ & 26 & $S \beta-T$ & CF & MI & 9.1 & 7.4 & 27 & 18 \\
\hline $\mathrm{F}$ & 26 & SS & $6 / 24$ & RH & 8.7 & 11.1 & 20 & 18 \\
\hline
\end{tabular}

$\mathrm{Hb}$, haemoglobin; $\mathrm{Hb} \mathrm{F}$, haemoglobin $\mathrm{F}$; $\mathrm{PCV}$, packed cell volume; $\mathrm{RDW}$, red cell distribution width; $\mathrm{S} \beta-\mathrm{T}, \mathrm{S} \beta$ thalassaemia; NPL, no perception of light; PL, perception of light; CF, counting fingers; Cat. cataract; RD, retinal detachment; Toxo., toxoplasmosis; MI, macular ischaemia; RH, retinal haemorrhage.

${ }^{a}$ Data not available.

cular changes, haemorrhages, chorioretinal scars and proliferative sickle retinopathy (PSR) were recorded using retinal drawings while the peripheral angiographic appearances were photographed in accordance with the same procedure employed by the Jamaican Sickle Cohort study of sickle cell disease. ${ }^{9}$ After an intravenous bolus dose of $5 \mathrm{ml} \mathrm{20 \%}$ sodium fluorescein the temporal peripheral retinal vasculature and posterior pole were photographed using a Zeiss fundus camera (Zeiss, Oberkochen, Germany) and FP4 black and white film. All angiograms were reported by one of us (A.C.B.) without prior knowledge of the haemoglobinopathy. The peripheral angiographic appearances were categorised using a recently proposed classification of sickle cell retinopathy. ${ }^{10}$

\section{Classification of Sickle Cell Retinopathy}

Type I: This pattern was quantitatively similar to normal. It required that the capillaries became gradually less dense in distribution and longer as the border was approached, and that the border was smooth and formed of arteriovenous loops of varying length. Additional features allowed within this category included avascular lacunas within the capillary bed, hairpin loops or tortuous vessels (Fig. 1).

Type II: The peripheral retinal vasculature differed from the normal pattern because a sharp demarcation existed between perfused and non-perfused retina with abrupt terminations of small or medium-calibre vessels, and a dense capillary bed up to the margin of perfusion giving an irregular or 'moth-eaten' appearance to the border. Type II presented two morphological patterns. In some cases there were capillary 'buds' or 'stumps' extending from the border of the vasculature into the non-perfused retina, which were sometimes hyperfluorescent or leaked fluorescein. In some cases the capillary 'buds' or 'stumps' showed bifurcations which simulated the capillary pattern seen when there is active reperfusion of recently infarcted retina. A border with this feature was classified as IIa (Figs. 2, 3), and otherwise as IIb (Figs. 4, 5).
Table II. Retinopathy grade of eyes examined and its distribution

\begin{tabular}{lcc}
\hline Grade & Male & Female \\
\hline I & 18 & 14 \\
IIa & 11 & 10 \\
IIb & 11 & 13 \\
III & 5 & 4 \\
IV & 5 & 7 \\
\hline
\end{tabular}

Type III: The pattern was indeterminate because recent acute arteriolar occlusion involving the vascular border had given rise to a type II pattern, which may have reverted to normal following subsequent reperfusion of the vascular bed. The recent nature of the obstruction was identified by the presence of an abrupt cessation of the intravascular dye column of an arteriole with a hypofluorescent column extending beyond it due to absorption of light by intravascular blood or altered blood products (Fig 6 ). An eye was not classified as type III if other regions of the border could be classified as type II.

Type IV: The angiogram was designated as type IV and unreadable if the photographs were blurred due to astigmatic aberration, the edge had not been photographed or the fluorescence was too faint.

\section{RESULTS}

The 50 patients consisted of 26 males and 24 females with a genotype distribution of $37 \mathrm{SS}, 9 \mathrm{SC}$ and $4 \mathrm{~S} \beta$-thalassaemia. Average age for the male patients was 30.4 years (range 16-53 years), and 33 years (range 18-55 years) for the female patients. Of the 100 eyes examined, 98 could be assessed with respect to the sickle retinopathy classification of the peripheral retinal vasculature. Two had longstanding retinal detachments. Eighty-nine of the total number of eyes had a visual acuity of $6 / 6$ or better (Fig. 7). Only 7 eyes had a visual acuity of $\leqslant 6 / 18$. One patient was excluded because of the presence of retinitis pigmentosa. One eye with an acuity of no perception of light (NPL) had a dense cataract and a tractional retinal detachment and one eye had perception of light (PL) with a long-standing retinal detachment. The other 3 eyes had macular problems: 1 had a chorioretinal scar possibly due to toxoplasmosis, 1 had macular ischaemia and the third had a retinal haemorrhage encroaching onto the fovea (Table I).

Thirty-two eyes (32.7\%) were grade I, 45 eyes ( $45.9 \%)$ were grade II, 9 eyes $(9.2 \%)$ were grade III while 12 eyes (12.2\%) were grade IV (Table II). Of the eyes classified as grade II, 21 were grade IIa while 24 belonged to the IIb category. Seventeen eyes (17.4\%) out of the total number had evidence of PSR with 10 of the eyes belonging to male patients; 9 were genotype SS and the remainder were SC. Eleven of the eyes had visual acuity of $6 / 6$ or better while 4

Table III. Comparison of patients with grade I versus grade II retinopathy

\begin{tabular}{lccccccccc}
\hline & Male & Female & Av. age $(\mathrm{yr})$ & $\mathrm{Hb}(\mathrm{g} / \mathrm{dl})$ & $\mathrm{HbF}(\%)$ & $\mathrm{PCV}(\%)$ & $\mathrm{RDW}(\%)$ & $\begin{array}{c}\text { Days in } \\
\text { hospital }\end{array}$ & $\begin{array}{c}\text { Adverse } \\
\text { experiences }\end{array}$ \\
\hline Grade I & 11 & 12 & 29 & 8.8 & 7.6 & 25.6 & 21.4 & 10.7 & 7 \\
Grade II & 12 & 11 & 33 & 9.5 & 4.2 & 28.4 & 18.9 & 10.9 & 6 \\
\hline
\end{tabular}




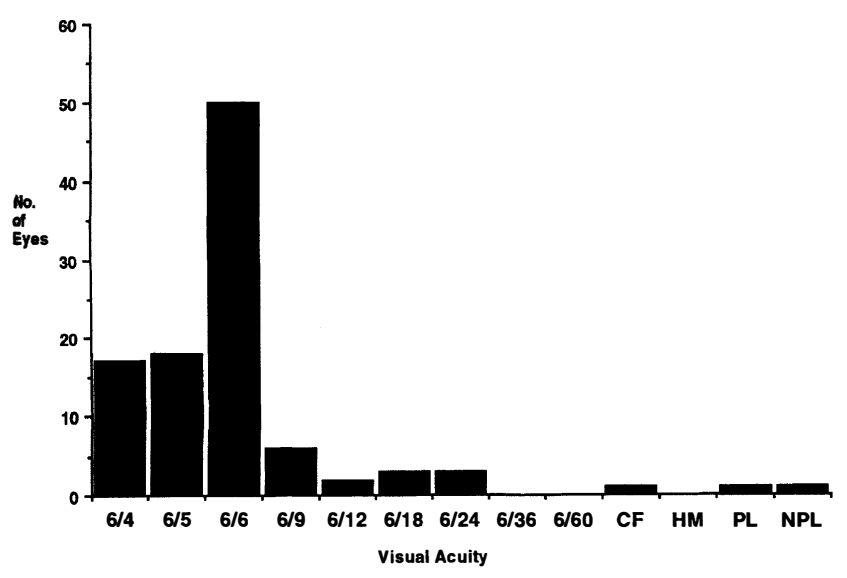

Fig. 7. Visual acuity in all eyes examined.

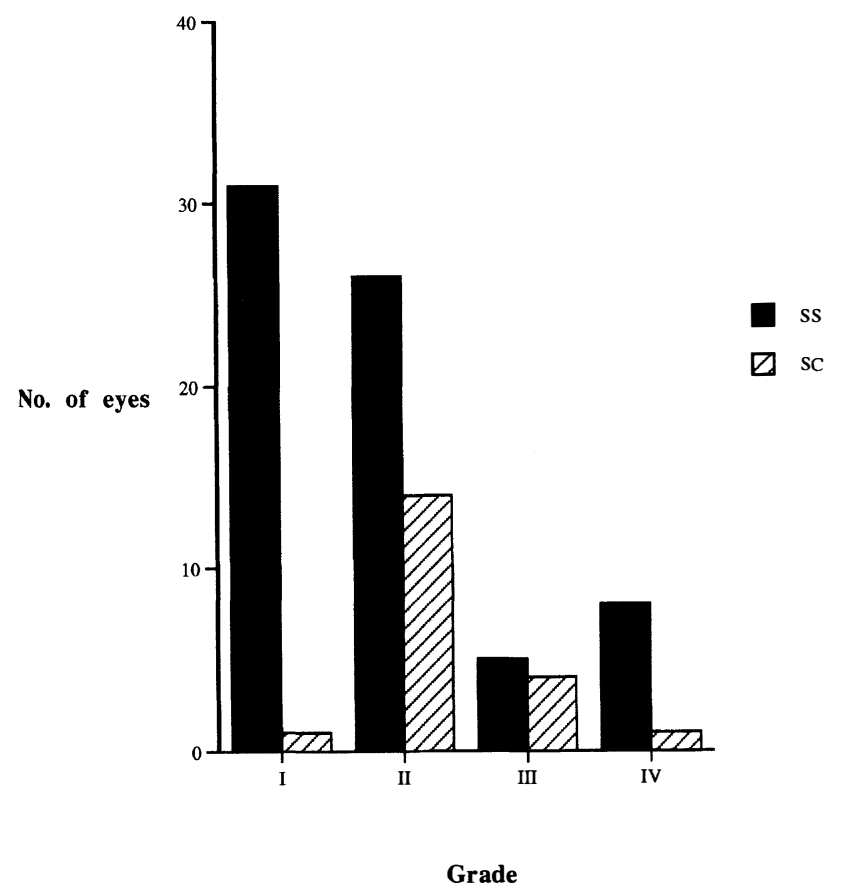

Fig. 8. Distribution of grade of retinopathy in eyes of SS and SC patients.

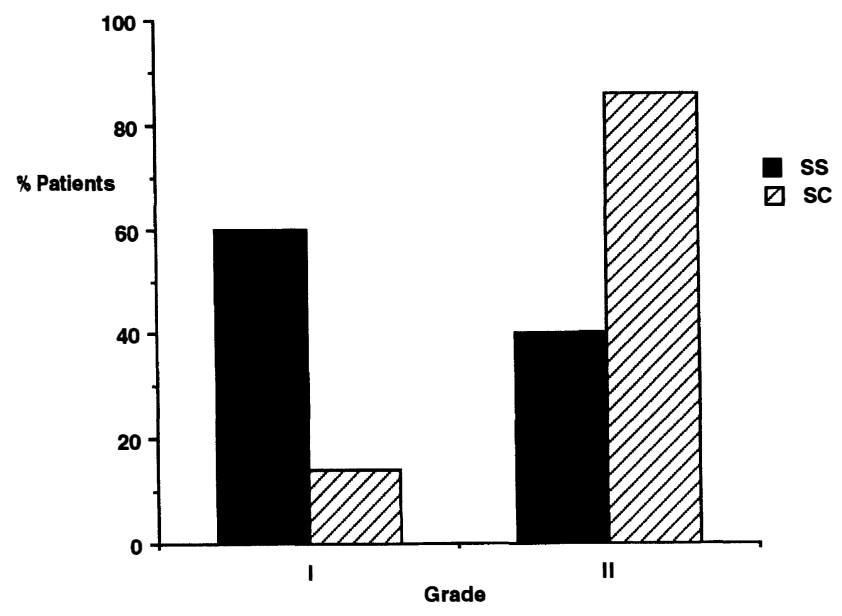

Fig. 9. Percentage of patients with SS and SC disease in grade I and II retinopathy groups. eyes could see 6/9, one had PL and one had NPL. Both patients with retinal detachment had the SC genotype. Bilaterality was a feature in 3 male patients and 2 female patients. There was a markedly increased prevalence of grade I retinopathy amongst eyes of patients with SS genotype ( $\mathrm{SS}: \mathrm{SC}=31: 1)$ while grade II was much commoner with SC genotype (SS:SC=26:14) (Fig. 8). The proportion of patients having grade II retinopathy in the worse-affected eye is markedly higher amongst patients with SC disease (86\%) compared with those with SS disease (40\%) (Fig. 9).

Laboratory values analysed were haemoglobin, haemoglobin F (Hb F), packed cell volume (PCV) and red cell distribution width (RDW). The mean haemoglobin for the series was $9.23 \mathrm{~g} / \mathrm{dl} \pm 1.65$, while the mean $\mathrm{Hb} \mathrm{F}$ was $6.25 \% \pm 4.92$. Equivalent values for the PCV and the RDW were $27 \% \pm 5.36$ and $20.1 \% \pm 4.12$. With respect to these values, the mean $\mathrm{Hb} \mathrm{F}$ for the subgroup with visual acuity $\leqslant 6 / 18$ was $5.4 \%$, which was only slightly lower than the overall mean of $6.25 \%$. Also the mean values for the PCV and RDW were $25.8 \%$ and $19.3 \%$ respectively, both of which are again not significantly different. Therefore no apparent correlation was found between these parameters and visual impairment. However, when the same parameters were correlated with the grade of retinopathy in the worse-affected eye, comparing patients with grade I and grade II retinopathy (Table III) the mean value of $\mathrm{HbF}$ percentage was found to be significantly higher in patients with grade I (7.6) compared with those with grade II (4.2) ( $p=0.0127)$.

The average length of stay in hospital during the year preceding the ophthalmic examination was 27.9 days, but this value does not reflect an even distribution as 27 of the patients were not hospitalised at all for the period and just 7 patients each spent more than 50 days in hospital. Average hospital stay for the group with visual acuity $\leqslant 6 / 18$ was 24 days while the overall mean was 22.9 days. There was still no correlation when 3 patients with known psychiatric disorder, that may have accounted for their lengthy admissions, were excluded. There was also no difference between the number of days spent in hospital by patients with grade I ( 10.7 days) and those with grade II (10.9 days) retinopathy. The number of patients who had suffered other adverse experiences including avascular hip necrosis, sickle chest and osteomyelitis was also very similar in these two groups (7 patients with grade I and 6 with grade II).

\section{DISCUSSION}

Sickle cell disease is one of the commonest genetic disorders. There has been a marked increase in the number of patients with sickle cell disease in the United Kingdom in the past few decades, mostly due to immigration, initially from the West Indies but more recently from Africa. A recent neonatal study in the Camberwell district alone found that 1 in 200 babies was affected with sickle cell disease, which is about 20 new cases each year. ${ }^{11}$ The variability in the manifestations of this condition can be partly 
accounted for by the environmental elements, which are not yet fully understood. Sickle cell retinopathy is one of the most common causes of peripheral proliferative retinopathy ${ }^{6}$ and continues to be a potential source of visual loss. Previous studies have shown that the most likely cause of severe visual impairment is proliferative retinopathy and its complications - vitreous haemorrhage, vitreous traction and retinal detachment. ${ }^{12}$ Patients with the SC genotype appear to be more at risk of such complications but no other predisposing factors have been identified. Large screening programmes are therefore needed to help identify those patients at risk of serious ocular complications. In the United Kingdom no study has looked at the prevalence of sickle retinopathy while many of the studies performed elsewhere did not include detailed fundus fluorescein angiography.

This study found that visual loss (visual acuity $\leqslant 6 / 18$ ) had occurred in only 7 eyes ( 6 patients). Two eyes had retinitis pigmentosa and in only $4(4 \%)$ could the visual loss be directly attributed to sickle cell retinopathy. Of note was the fact that visual acuity in patients with PSR was normal (6/6 or better) in 11 of the eyes, 6/9 in 4 eyes, and was PL and NPL in the 2 eyes with retinal detachment.

The majority of patients screened so far had the SS genotype, which reflects the genotype prevalence in the local sickle cell community (SS:SC $=15: 1$ ). The incidence of visual loss in this group appears to compare with that seen amongst the usually more seriously affected patients with SC disease; however, larger numbers are required in order to reach statistical significance. Our results concur with studies performed in Jamaica with regard to the increased risk of visual morbidity amongst patients with PSR. We have also found grade II retinopathy, which is thought to be more likely to progress to PSR and subsequently lead to visual impairment, to be commoner in patients with SC disease. Assessment of the patients' haematological and clinical profiles has so far revealed only one significant correlation. The $\mathrm{Hb} \mathrm{F}$ was lower in those patients with grade II changes in their worse eye relative to those with grade I, which supports the suspected protective effect of $\mathrm{Hb}$. This also suggests that a diagnosis of grade II retinopathy may have a predictive value. It is interesting that none of the 98 eyes where funduscopy was performed had angioid streaks. The latter are thought to be a common association with sickle cell disease ${ }^{13}$ and may lead to disciforms, which accounted for $57 \%$ of the causes of visual impairment in patients without PSR in Jamaica. ${ }^{13}$ Angioid streaks are not commonly seen in children and it is possible that chronic haemolysis results in the deposition of iron in Bruch's membrane, rendering it more liable to crack formation, but the incidence in an adult population would be expected to be about $6 \% .^{14,15}$
The recruitment of sickle cell patients has proved to be a difficult task as most of them will have no visual symptoms until serious complications occur. Furthermore, those patients who have other significant systemic manifestations are understandably reluctant to attend the hospital for what may appear to be an unnecessary visit. The long-term assessment of patients who have been screened and the recruitment of larger numbers, together with detailed analysis of chromosomal haplotypes and other systemic associations, may provide further useful clues as to the natural history of sickle cell retinopathy in Britain.

We are indebted to the Locally Organised Research Scheme (LORS) for the funding of this screening programme and to our colleagues Miss Watson and Miss Hingorani for their help. We are grateful to $\mathrm{Mr} \mathrm{C}$. Clements for the ophthalmic photography and to Mrs E. Cobb and Ms J. Yates for their assistance in recruiting the patients.

Key words: Retinopathy, Screening, Sickle cell.

\section{REFERENCES}

1. Tuck S, White JM. Sickle cell disease. In: Studd J, editor. Progress in obstetrics and gynaecology, vol 1. London: Churchill Livingstone, 1981:70-8.

2. Serjeant GR, Richards R, Barbor PRH, Milner PF. Relatively benign sickle cell and anaemia in 60 patients aged over 30 in the West Indies. BMJ 1968;3:86-91.

3. Bonamoni MT, Cunha SL, de-Aravjo JJ. Funduscopic alterations in SS and SC haemoglobinopathies: study of a Brazilian population. Ophthalmologica 1988;197:26-33.

4. Talbot JF, Bird AC, Maude GH, Acheson RW, Moriarty BJ, Sergeant GR. Sickle cell retinopathy in Jamaican children: further observations from a cohort study. $\mathrm{Br} \mathrm{J}$ Ophthalmol 1988;72:727-32.

5. Goldberg MF. Natural history of untreated proliferative sickle retinopathy. Arch Ophthalmol 1971;85:428-37.

6. Brown GC, Brown RH, Brown MM. Peripheral proliferative retinopathies. Int Ophthalmol 1987;11:41-50.

7. Kehinde MO, Marsh JC, Marsh GW. Sickle cell disease in North London. Br J Haematol 1987;66:543-7.

8. Brozovic M, Aniowu E. Sickle cell disease in Britain. J Clin Pathol 1984;37:1321-6.

9. Serjeant GR, Grandison Y, Lowrie Y, et al. The development of haematological changes in homozygous sickle cell disease: a cohort study from birth to 6 years. Br J Haematol 1981;48:533-43.

10. Penman AD, Talbot JF, Chuang EL, et al. New classification of peripheral retinal vascular changes in sickle cell disease. Br J Ophthalmol 1994;78:681-9.

11. Horn MB, Frost B, Davis LR, Bellingham AJ, Stroud CB, Studd JW. Neonatal screening for sickle disease in Camberwell: results and recommendations of a 2 year pilot study. $\mathrm{Br}$ Med J Clin Res 1986;292:737-40.

12. Moriarty BJ, Acheson RW, Condon PI, Sergeant GR. Patterns of visual loss in untreated sickle cell retinopathy. Eye 1988;2:330-5.

13. Nagpal KC, Asdourian G, Goldbaum M, et al. Angioid streaks and sickle cell haemoglobinopathies. Br J Ophthalmol 1976;63:31-4.

14. Paton D. The relation of angioid streaks to systemic disease. Springfield, IL: Thomas, 1972.

15. Geeraets WJ, Guerry D, III. Angioid streaks and sickle cell disease. Am J Ophthalmol 1960;49:450. 